\title{
Crystal structure and XANES investigation of petzite, $\mathrm{Ag}_{3} \mathrm{AuTe}_{2}$
}

\section{Hidetomo Hongu, Akira Yoshiasa, Massimo Nespolo, Tsubasa Tobase, Makoto Tokuda and Kazumasa Sugiyama}

Acta Cryst. (2019). B75, 273-278

\section{IUCr Journals CRYSTALLOGRAPHY JOURNALS ONLINE}

Copyright (C) International Union of Crystallography

Author(s) of this article may load this reprint on their own web site or institutional repository provided that this cover page is retained. Republication of this article or its storage in electronic databases other than as specified above is not permitted without prior permission in writing from the IUCr.

For further information see http://journals.iucr.org/services/authorrights.html 
STRUCTURAL SCIENCE CRYSTAL ENGINEERING MATERIALS

ISSN 2052-5206

Received 21 December 2018

Accepted 10 February 2019

Edited by J. Hadermann, University of Antwerp, Belgium

Keywords: petzite; gold minerals; single-crystal structure analysis; Au L-edge XANES; Debye temperature.

CCDC reference: 1896511

Supporting information: this article has supporting information at journals.iucr.org/b

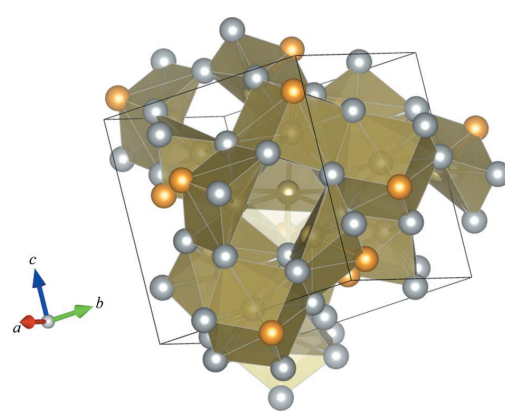

C 2019 International Union of Crystallography

\section{Crystal structure and XANES investigation of petzite, $\mathrm{Ag}_{3} \mathrm{AuTe}_{2}$}

\author{
Hidetomo Hongu, ${ }^{a *}$ Akira Yoshiasa, ${ }^{a}$ Massimo Nespolo, ${ }^{b}$ Tsubasa Tobase, ${ }^{c}$ \\ Makoto Tokuda ${ }^{a}$ and Kazumasa Sugiyama ${ }^{d}$
}

\begin{abstract}
${ }^{\mathbf{a}}$ Faculty of Advanced Science and Technology, Kumamoto University, Kumamoto 860-8555, Japan, ${ }^{\mathbf{b}}$ Université de Lorraine, CNRS, CRM2, Nancy, France, 'Center for High Pressure Science and Technology Advanced Research (HPSTAR), Shanghai, People's Republic of China, and Institute for Materials Research, Tohoku University, Sendai 980-8577, Japan. *Correspondence e-mail: stnjjrg9135@mb.pikara.ne.jp
\end{abstract}

Petzite, $\mathrm{Ag}_{3} \mathrm{AuTe}_{2}$, crystallizes in the space group $I_{1} 32$, which is a Sohncke type of space group where chiral crystal structures can occur. The structure refinement of petzite reported long ago [Frueh (1959). Am. Mineral. 44, 693701] did not provide any information about the absolute structure. A new singlecrystal X-ray diffraction refinement has now been performed on a sample from Lake View Mine, Golden Mile, Kalgoorlie, Australia, which has resulted in a reliable absolute structure [a Flack parameter of 0.05 (3)], although this corresponds to the opposite enantiomorph reported previously. The minimum Te-Te distance is 3.767 (3) $\AA$, slightly shorter than the van der Waals bonding distance, which suggests a weak interaction between the two chalcogens. XANES spectra near the $\mathrm{Au}$ and $\mathrm{Te} L_{\mathrm{III}}$ edges suggest that the chemicalbonding character of $\mathrm{Au}$ in petzite is more metallic than in other gold minerals.

\section{Introduction}

Nearly 30 kinds of mineral in which gold is a major component have been confirmed to date, like calaverite $\mathrm{AuTe}_{2}$, sylvanite $(\mathrm{Au}, \mathrm{Ag})_{2} \mathrm{Te}_{4}$, krennerite $(\mathrm{Au}, \mathrm{Ag})_{2} \mathrm{Te}_{4}$ and petzite $\mathrm{Ag}_{3} \mathrm{AuTe}_{2}$, besides native gold. They occur both isolated and in association with other gold minerals. Reports of gold minerals are not infrequent. Gold and silver belong to the coinage metals group in the periodic table of the elements; they give extensive solid solutions in compounds, including minerals, and also form an alloy, known as electrum. Gold minerals often include heavy pnictogens and chalcogens ( $\mathrm{Sb}, \mathrm{Bi}, \mathrm{Se}, \mathrm{Te})$; in particular, several gold and tellurium/antimony compounds are known, with a simple chemical formula, like calaverite and sylvanite, but their crystal structures are far from simple, showing incommensurate modulation under ambient conditions (Schutte \& Boer, 1988; Pertlik, 1984; Reithmayer et al., 1993; Bindi et al., 2009; Bindi \& Chapuis, 2017). Even the pure unsubstituted calaverite $\mathrm{AuTe}_{2}$ shows a periodic ordered structure only under high-pressure conditions (Reithmayer $e t$ al., 1993).

Petzite, $\mathrm{Ag}_{3} \mathrm{AuTe}_{2}$, coexists with coloradoite, $\mathrm{HgTe}$, and hessite, $\mathrm{Ag}_{2} \mathrm{Te}$; it was first synthesized by Thompson (1948) and its crystal structure was determined by Frueh (1959) with a Buerger precession camera from a fragment obtained by fracturing a crystal of hessite in which it occurred as irregularshaped blobs (Frueh, 1959). The crystal structure was later refined by Chamid et al. (1978). Thompson $(1948,1949)$ indicated that petzite is a compound with a definite silver-to-gold ratio, which suggests distinct ordered positions for the silver and gold atoms, corresponding to a three-dimensionally 
periodic non-modulated structure, unlike calaverite and sylvanite. Hessite occurs in two polymorphs, the lowtemperature $\beta$ phase (space-group type $P 2_{1} / c$ ) and the hightemperature $\alpha$ phase (space-group type $F m 3 m$ ) (Schneider \& Schulz, 1993), whereas no polymorphism has been confirmed in either coloradoite (space-group type $F 43 m$ ) or petzite (space-group type $14{ }_{1} 32$ ). Frueh (1959) quoted an unpublished thermal analysis showing a transition in petzite at $483 \pm 10 \mathrm{~K}$; if confirmed, such a transition would lead to a holohedral polymorph which would make possible a petzite-hessite solid solution at high temperature. Frueh (1959) reported, but did not index, a powder diffractogram at $523 \mathrm{~K}$ which differed from that at room temperature; however, microscopic observation showed only a limited shrinking of the crystal, attributed to diffusion of gold in hessite following a higher solubility at high temperature. However, no transformation twinning in heat-treated samples was reported, as one would expect if a phase transition had taken place.

In this study, we have performed a precise structural analysis of petzite crystal samples and clarified the structure details, the site occupancy on each site and the bonding character. In addition, $\mathrm{Au}$ and $\mathrm{Te} L_{\mathrm{III}}$-edge XANES measurements have been performed to investigate detailed bonding characteristics such as electrical properties.

\section{Experimental}

\subsection{Chemical analyses}

Single crystals of $\mathrm{Ag}_{3} \mathrm{AuTe}_{2}$ petzite were obtained from Lake View Mine, Golden Mile, Kalgoorlie, Australia (Kumamoto University, sample reference C133-petzite-single-grain201532). The sample is brittle, of a deep steel-grey colour and with large single crystals several millimetres in size. Its chemical composition was determined with a JEOL scanning electron microscope (SEM, JSM-7001F operated at $15 \mathrm{kV}$, $0.5 \mathrm{~mA}$ ) equipped with an Oxford energy-dispersive X-ray spectroscope (EDS, INCA system) (Hongu et al., 2018). Each pure metal was used as a standard material and the ZAF (atomic number $Z$, absorption A and fluorescence F) corrections were applied. Measurement points where the total clearly deviated from $100 \%$ were excluded. The weight percentages of $\mathrm{Au}, \mathrm{Ag}$ and $\mathrm{Te}$ were $25.25-25.98 \mathrm{wt} \% \mathrm{Au}$, 41.55-42.26 wt \% Ag and 33.01-34.14 wt \% Te. The variation in molar ratio among numerous analytical points with respect to the stoichiometric values was less than a few per cent. Only trace amounts of mercury were detected. Impurities such as arsenic and antimony were below the detection threshold.

\subsection{Single-crystal $X$-ray diffraction experiments and structure refinements.}

We performed single-crystal X-ray diffraction experiments on petzite with a Rigaku R-AXIS RAPID diffractometer (Tokuda et al., 2018; Hongu et al., 2018). Reflection conditions were consistent with space group $I 4_{1} 32$. Intensities were measured using graphite-monochromated Mo $K \alpha \quad(\lambda=$ $0.71069 \AA$ ) radiation. The data were corrected for Lorentz and
Table 1

Experimental details.

\begin{tabular}{ll}
\hline Crystal data & \\
Chemical formula & $\mathrm{Ag}_{3} \mathrm{AuTe}_{2}$ \\
$M_{\mathrm{r}}$ & 775.8 \\
Crystal system, space group & Cubic, ${ }_{1} 32$ \\
Temperature $(\mathrm{K})$ & 297 \\
$a(\AA)$ & $10.417(8)$ \\
$V\left(\AA^{3}\right)$ & $1130.3(15)$ \\
$Z$ & 8 \\
Radiation type & Mo $K \alpha$ \\
$\mu\left(\mathrm{mm}^{-1}\right)$ & 46.08 \\
Crystal size $(\mathrm{mm})$ & $0.07 \times 0.05 \times 0.03$ \\
& \\
Data collection & \\
Diffractometer & Rigaku R-AXIS RAPID \\
Absorption correction & Integration (Busing \& Levy, 1957) \\
$T_{\text {min }}, T_{\text {max }}$ & $0.085,0.251$ \\
No. of measured, & $2866,225,176$ \\
$\quad$ independent and & \\
$\quad$ observed $[I>3 \sigma(I)]$ & \\
reflections & \\
$R_{\text {int }}$ & \\
$(\text { sin } \theta / \lambda)_{\text {max }}\left(\AA^{-1}\right)$ & 0.097 \\
& 0.648 \\
Refinement & \\
$R\left[F^{2}>2 \sigma\left(F^{2}\right)\right], w R\left(F^{2}\right), S$ & $0.030,0.052,1.04$ \\
No. of reflections & 225 \\
No. of parameters & 12 \\
$\Delta \rho_{\text {max }}, \Delta \rho_{\text {min }}\left(\mathrm{e} \AA^{-3}\right)$ & $1.74,-1.03$ \\
Absolute structure & 71 Friedel pairs used in the refinement \\
Absolute structure parameter & Flack, $0.05(3)$ \\
\hline
\end{tabular}

polarization factors and for the effect of absorption, which was determined using the integration method based on the observed shape of the specimens. Data reduction results in $R_{\text {int }}=0.0968$ which, although rather high, is not unusual for a sample containing heavy atoms.

Independent reflections were used for refinement with $I>$ $3 \sigma(I)$ by full matrix-least-squares methods. Experimental details are listed in Table 1. Refinement calculations were performed using the program JANA2006 (Petříček et al., 2014). The refinement converged smoothly to $R_{1}=0.0297$. An attempt to refine mixed-occupancy $\mathrm{Ag} / \mathrm{Au}$ on the $8 b$ and $24 f$ positions did not give any indication of isomorphic substitution, confirming the $\mathrm{Ag} / \mathrm{Au}$ ordering already reported in previous studies. The residual peaks $\left(1.74,-1.03 \AA^{\circ} \mathrm{e}^{-3}\right)$ are acceptable for a crystal structure containing heavy atoms, considering the difficulties in the absorption correction.

The space group of petzite belongs to a Sohncke type, which means that the structure can occur in two enantiomorphic configurations. The Flack parameter (Flack, 1983) refined to 0.05 (3), confirming that the absolute structure is correct. The crystal structure is shown in Figs. 1-3. The interatomic distances for petzite and the structure refinement data, atomic coordinates and anisotropic atomic displacement parameters are given in Tables 2 and 3, respectively.

\subsection{XANES measurements}

The XANES spectra near the $\mathrm{Au}$ and Te $L_{\mathrm{III}}$ edges were measured in fluorescent mode on beamline BL-9C PF, KEK, Tsukuba, Japan. We also measured several Au and Te minerals 
for comparison [aurostibite $\mathrm{AuSb}_{2}$ from Krasna Hora, Schoenberg, Czech Republic; calaverite $\mathrm{AuTe}_{2}$ from Lake View Mine, Golden Mile, Kalgoorlie, Australia; sylvanite (Ag, $\mathrm{Au}) \mathrm{Te}_{2}$ from Emperor Mine, Vatukoula, Viti Levu, Fiji; krennerite $\mathrm{Au}_{3} \mathrm{AgTe}_{8}$ from Cripple Creek, Colorado, USA; nagyágite $\left[\mathrm{Pb}_{3}(\mathrm{~Pb}, \mathrm{Sb})_{3} \mathrm{~S}_{6}\right](\mathrm{Au}, \mathrm{Te})_{3}$ from Sacaramb (Nagyág), Transylvania, Romania; and emmonsite $\mathrm{Fe}^{3+}{ }_{2} \mathrm{Te}_{3}^{4+} \mathrm{O}_{9} \cdot 2 \mathrm{H}_{2} \mathrm{O}$ from San Miguel Mine, Moctezuma, Sonora, Mexico], all property of Kumamoto University. The synchrotron radiation was monochromated by an $\mathrm{Si}(111)$ double-crystal monochromator. X-ray energy calibration was performed by setting the copper metal pre-edge absorption peak to $8978.8 \mathrm{eV}$. Mirrors were used to eliminate higher harmonics. The measurements were performed using the usual energy resolution to obtain sufficient X-ray flux and for comparison with published results. The details of the measurements are given in the literature (Hiratoko et al., 2013; Tobase et al., 2018; Yoshiasa et al., 2018).

\section{Results and discussion}

3.1. Description of the structure and bonding distances in petzite

The crystal structure of petzite was refined by Chamid et al. (1978) in the space group $14_{1} 32$, which is a Sohncke type of space group where chiral structures can occur (Nespolo et al., 2018). However, no attempt was made to determine the absolute structure and the structural model essentially coincides with that proposed earlier by Frueh (1959). In this model, the gold atom is coordinated by two tellurium atoms at $2.61 \AA$ and six silver atoms at $3.06 \AA$; the silver atoms are tetrahedrally surrounded by Te atoms, with two of the Te

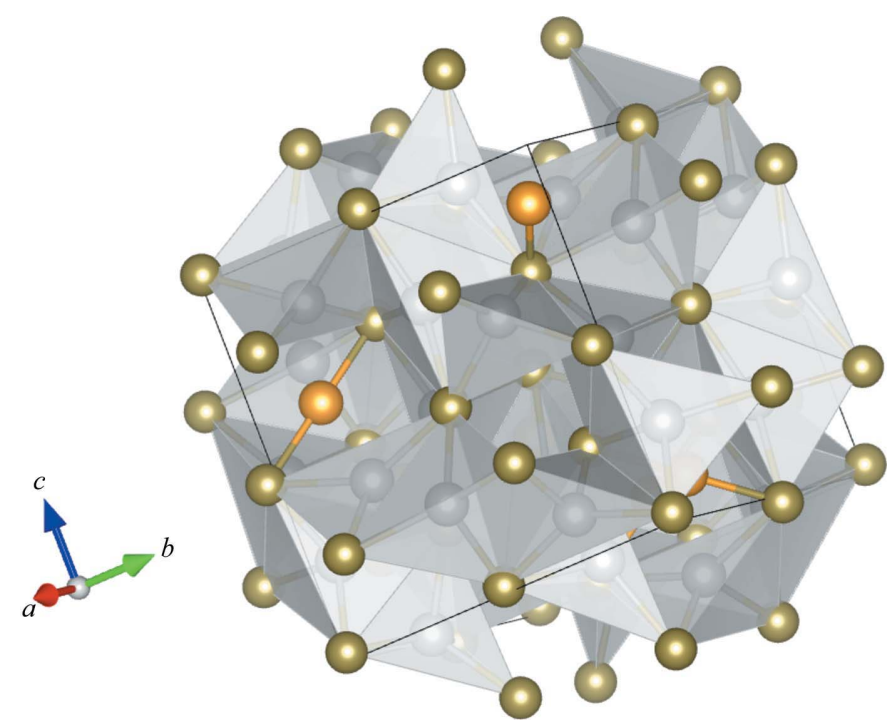

Figure 1

The cation-centred description of the crystal structure of petzite. In this description, the structure is based on clusters of six edge-sharing $\mathrm{AgTe}_{4}$ rhombic disphenoids with a common corner, the $\mathrm{AuTe}_{2}$ dumbbell being located in the cavity surrounded by clusters. Figure drawn with VESTA (Momma \& Izumi, 2011).
Table 2

Interatomic bond distances in petzite.

\begin{tabular}{lll}
\hline Atom 1 & Atom 2 & Distance $(\AA)$ \\
\hline $\mathrm{Au}$ & $\mathrm{Te}$ & $2.6273(13)$ \\
$\mathrm{Au}$ & $\mathrm{Ag}$ & $3.0784(18) \times 6$ \\
$\mathrm{Au}$ & $\mathrm{Au}$ & $3.6833(3)$ \\
$\mathrm{Ag}$ & $\mathrm{Te}$ & $2.9140(18) \times 3$ \\
$\mathrm{Ag}$ & $\mathrm{Te}$ & $2.9825(19) \times 3$ \\
$\mathrm{Ag}$ & $\mathrm{Ag}$ & $3.0814(16) \times 2$ \\
$\mathrm{Ag}$ & $\mathrm{Ag}$ & $3.3053(17) \times 2$ \\
$\mathrm{Te}$ & $\mathrm{Te}$ & $3.767(3)$ \\
\hline
\end{tabular}

atoms at $2.92 \AA$ and two at $2.96 \AA$; the tellurium is coordinated by one gold atom at $2.61 \AA$, three silver atoms at $2.92 \AA$ and three more silver atoms at $2.96 \AA$. It was explained that the $\mathrm{Au}-\mathrm{Te}$ distance is shorter than the Ag-Te distances because there are only two close neighbours for $\mathrm{Au}$ in petzite.

Our results support the fully ordered model of petzite, with distinct ordered positions for $\mathrm{Au}$ and $\mathrm{Ag}$ atoms, proposed in the past by Thompson $(1948,1949)$, Frueh (1959) and Chamid et al. (1978). However, our model corresponds to the opposite handedness with respect to the previous reports. Au was refined on the Wyckoff $8 a$ position in the past, but on the $8 b$ position in our model. These two positions belong to the same Wyckoff set and are related by the additional generator of the Euclidean normalizer of $I 4_{1} 32$, which is precisely the inversion through the origin that exchanges the two handednesses. At the time of Frueh's (1959) investigation, it was not yet possible to determine an absolute structure. The more recent report by Chamid et al. (1978) did not determine the absolute configuration either. The opposite configuration reported previously may therefore have simply been the result of an arbitrary assignment.

The structure of petzite is shown in Figs. 1 and 2. In the cation-centred description (Fig. 1), the structure is based on

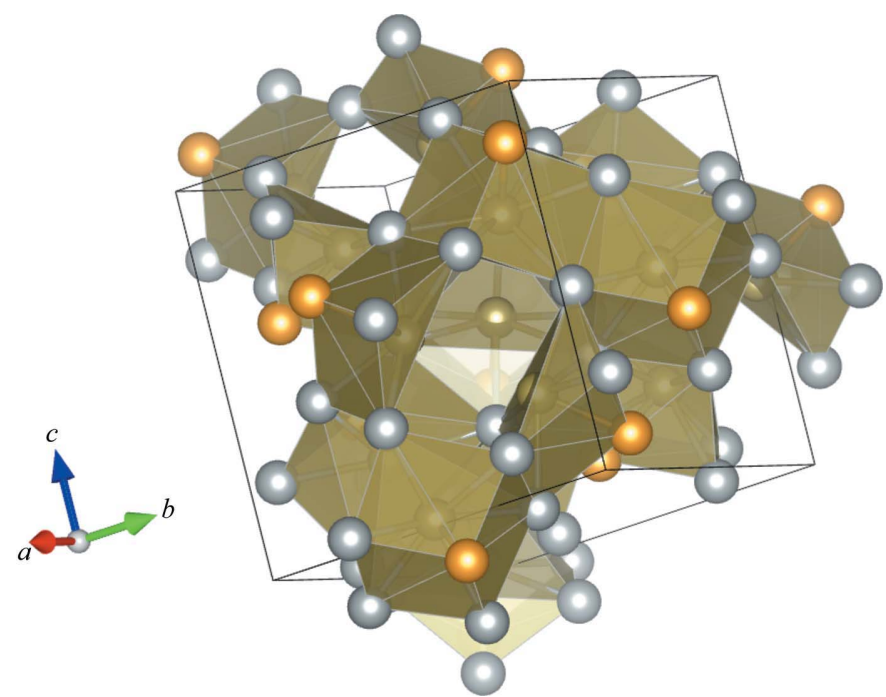

Figure 2

The anion-centred description of the crystal structure of petzite. In this description, tellurium is almost at the centre of a triangular face of a monocapped flattened trigonal antiprism $\mathrm{Te}\left[\mathrm{Ag}_{6} \mathrm{Au}\right]$. Figure drawn with VESTA 
Table 3

Atomic coordinates and anisotropic atomic displacement parameters for petzite.

\begin{tabular}{|c|c|c|c|c|c|c|c|c|c|}
\hline & $x$ & $y$ & $z$ & $U_{11}$ & $U_{22}$ & $U_{33}$ & $U_{23}$ & $U_{13}$ & $U_{12}$ \\
\hline Te $(16 e)$ & $0.22938(8)$ & $0.22938(8)$ & $0.22938(8)$ & $0.0286(4)$ & $0.0286(4)$ & $0.0286(4)$ & -0.0007 (4) & $-0.0007(4)$ & $-0.0007(4)$ \\
\hline $\mathrm{Ag}(24 f)$ & $-0.13818(15)$ & 0 & 0.25 & $0.0464(10)$ & $0.0389(9)$ & $0.0329(10)$ & 0 & 0 & $0.0052(7)$ \\
\hline
\end{tabular}

clusters of six edge-sharing $\mathrm{AgTe}_{4}$ rhombic disphenoids with a common corner, the $\mathrm{AuTe}_{2}$ dumbbell being located in the cavity surrounded by clusters. In the anion-centred description (Fig. 2), Te is almost at the centre of a triangular face of a monocapped flattened trigonal antiprism $\mathrm{Te}\left[\mathrm{Ag}_{6} \mathrm{Au}\right]$.

Selected interatomic distances are shown in Table 2. The Pauling ionic radii of $\mathrm{Ag}^{\mathrm{I}}, \mathrm{Au}^{\mathrm{I}}$ and $\mathrm{Te}^{-\mathrm{II}}$ are $1.26,1.37$ and $2.21 \AA$, respectively. The Shannon radii in sulfides are $0.92 \AA$ for ${ }^{[4]} \mathrm{Ag}^{\mathrm{I}}, 0.58 \AA$ for ${ }^{[2]} \mathrm{Au}^{\mathrm{I}}$ and $2.07 \AA$ for ${ }^{[6]} \mathrm{Te}^{-\mathrm{II}}$ (Shannon, 1981), whereas the covalent radii for $\mathrm{Ag}, \mathrm{Au}$ and Te are 1.45, 1.36 and $1.38 \AA$, respectively (Cordero et al., 2008).

The rhombic disphenoid around silver has two Ag-Te distances of 2.9140 (18) $\AA$ and the other two are 2.9825 (19) $\AA$; these are slightly shorter than the sum of the Shannon radii for sulfides $(2.99 \AA)$ and much shorter than the sum of the ionic radii $(3.47 \AA)$ but longer than the sum of the covalent radii $(2.83 \AA$ ) .

The gold atom is coordinated by two tellurium atoms forming a dumbbell with distances of 2.6273 (13) $\AA$, which is shorter than the bond distance for either ionic (3.58 $)$ or covalent $(2.74 \AA$ ) bonds, computed as the sum of the respective radii, but close to the sum of the Shannon radii for sulfides $(2.65 \AA)$. Frueh (1959) explained the shorter linear Au-Te distance with respect to the tetrahedral Ag-Te distances precisely in terms of the lower coordination for gold.

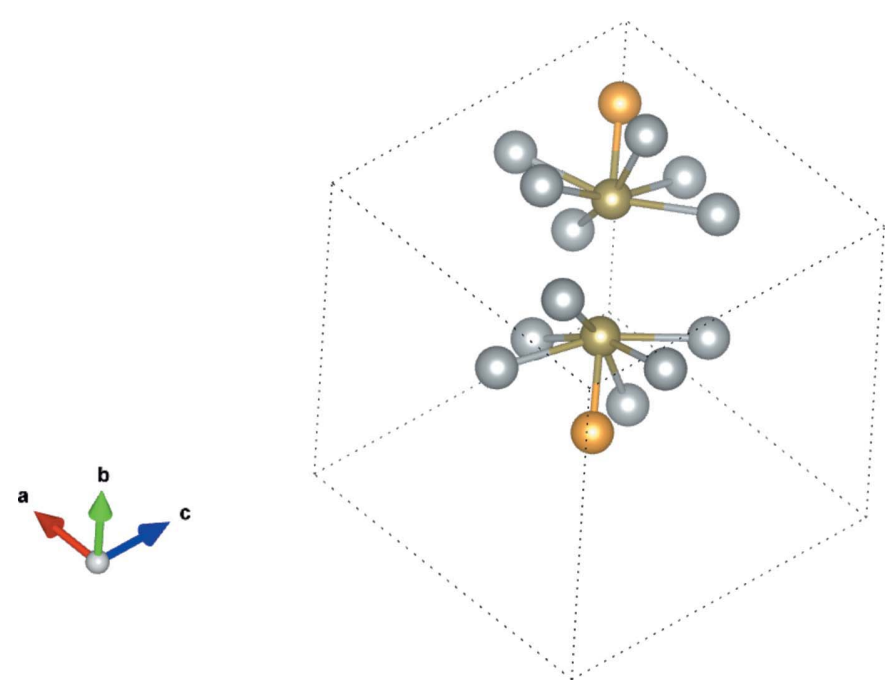

Figure 3

A portion of the crystal structure of petzite, showing the region around two neighbouring tellurium atoms. The silver and gold atoms coordinated to the same tellurium atom are all on the same side of a geometric plane, and two neighbouring tellurium atoms have their coordinating atoms on opposite sides of this plane, leaving an empty cavity in between, suggesting the presence of a weak $\mathrm{Te}-\mathrm{Te}$ bond. Figure drawn with VESTA.
Tellurium is coordinated by one gold atom at 2.6273 (13) and by six silver atoms, three at 2.9140 (18) $\AA$ and three more at 2.9825 (19) $\AA$. All seven atoms coordinating the tellurium are on the same side of a geometric plane, and two neighbouring tellurium atoms have their coordinating atoms on opposite sides of this plane, leaving an empty cavity in between (Fig. 3). The Te-Te distance $[\geq 3.767$ (3) $\AA$ ] is far larger than the sum of the covalent radii but shorter than the van der Waals bonding distance (van der Waals radius $1.99 \AA$; Alvarez, 2013), suggesting the presence of a weak $\mathrm{Te}-\mathrm{Te}$ bond, which is likely to be responsible for the brittle nature of petzite crystals.

The shortest distances for Ag-Au [3.0784 (18) A] and AgAg [3.0814 (16) $\AA$ ] are very close to each other but somewhat longer than the bond distances in electrum (where $\mathrm{Ag}$ and $\mathrm{Au}$ are disordered) or metallic silver ( 2.88-2.89 $\AA$; Wyckoff, 1963; Venudhar et al., 1978), which suggests the presence of a metallic bond.

\subsection{Temperature factor and estimated Debye temperature $\theta_{\mathrm{D}}$}

The anisotropic atomic displacement parameter for each atom in petzite is shown in Table 3. The temperature factor at each site in the petzite structure increases in the order of Te, $\mathrm{Ag}$ and $\mathrm{Au}$ sites. The $\mathrm{Au}$ atom in petzite has the largest amplitude of thermal vibration, which results from the covalent $\mathrm{Te}-\mathrm{Au}-\mathrm{Te}$ linear bond. The atomic displacement parameter relates to the mass of the atom.

The Debye temperature, $\theta_{\mathrm{D}}$, is one of the indices of a physical quantity by which comparison is possible. The Debye temperature $\theta_{\mathrm{D}}$ correlates with physical properties such as the hardness of crystals. The value of $\theta_{\mathrm{D}}$ for each atom can be estimated using the dynamic component in the Debye-Waller factor based on the Debye approximation (Willis \& Pryor, 1975; Wood et al., 2002; Christensen et al., 2006; Nakatsuka et al., 2011; Yoshiasa et al., 2016). We have estimated $\theta_{\mathrm{D}}$ for each atom using the values of $U$ (Table 3 ) under the assumption of no static disorder components of atoms. We obtained $\theta_{\mathrm{D}}$ values for $\mathrm{Au}, \mathrm{Ag}$ and $\mathrm{Te}$ in petzite of 73.3, 101.1 and $108.5 \mathrm{~K}$, respectively. These are significantly lower than the corresponding values in the pure metals $(178,221$ and $152 \mathrm{~K}$, respectively), reflecting the different binding forces in the telluride with respect to the respective metals.

\subsection{Au and Te $L_{I I I}$-edge XANES spectra and bonding character in petzite}

Many gold minerals and compounds are represented by simple chemical formulae and adopt basic structures. Auro- 
stibite, calaverite and sylvanite have structures related to pyrite- and $\mathrm{CdI}_{2}$-type structures. Compounds with gold and group V or group VI elements have semi-metallic properties. In the case of pyrite- and $\mathrm{CdI}_{2}$-type compounds, the bonding property among the group $\mathrm{V}$ or $\mathrm{VI}$ elements affects the main electrical properties. Petzite, $\mathrm{Ag}_{3} \mathrm{AuTe}_{2}$, contains more gold and silver than calaverite and sylvanite, and the metallic character of the bonding between gold and silver is recognized. On the other hand, the observed Te-Te distances do not support the existence of electron sharing among the tellurium atoms but only a weak interaction of van der Waals type.

On the high-energy side of the absorption edge in the $\mathrm{Au}$ $L_{\mathrm{III}}$-edge XANES spectrum, a strong first peak (white line) appears due to electron transfer from the $\mathrm{Au}$ atoms to the anions. This peak makes it possible to compare electron polarization, ionic and metallic character for Au atoms. Fig. 4 shows the $\mathrm{Au} L_{\mathrm{III}}$-edge XANES spectra for petzite and reference Au minerals. The shape of the XANES spectrum for petzite clearly resembles that of metallic gold, thus the chemical bonding of gold in petzite has a more pronounced metallic character than in other gold minerals.

Figs. 5(a) and 5(b) show the Te $L_{\mathrm{III}}$-edge XANES spectra and their first-derivative curves for petzite and reference $\mathrm{Te}$ minerals. Emmonsite, $\mathrm{Fe}^{3+}{ }_{2} \mathrm{Te}^{4+}{ }_{3} \mathrm{O}_{9} \cdot 2 \mathrm{H}_{2} \mathrm{O}$, is a tellurium salt with a transparent greenish yellow colour. Tellurium in this mineral is a tetravalent cation. The absorption edge of cationleaving electrons shifts to the higher energy side than that of

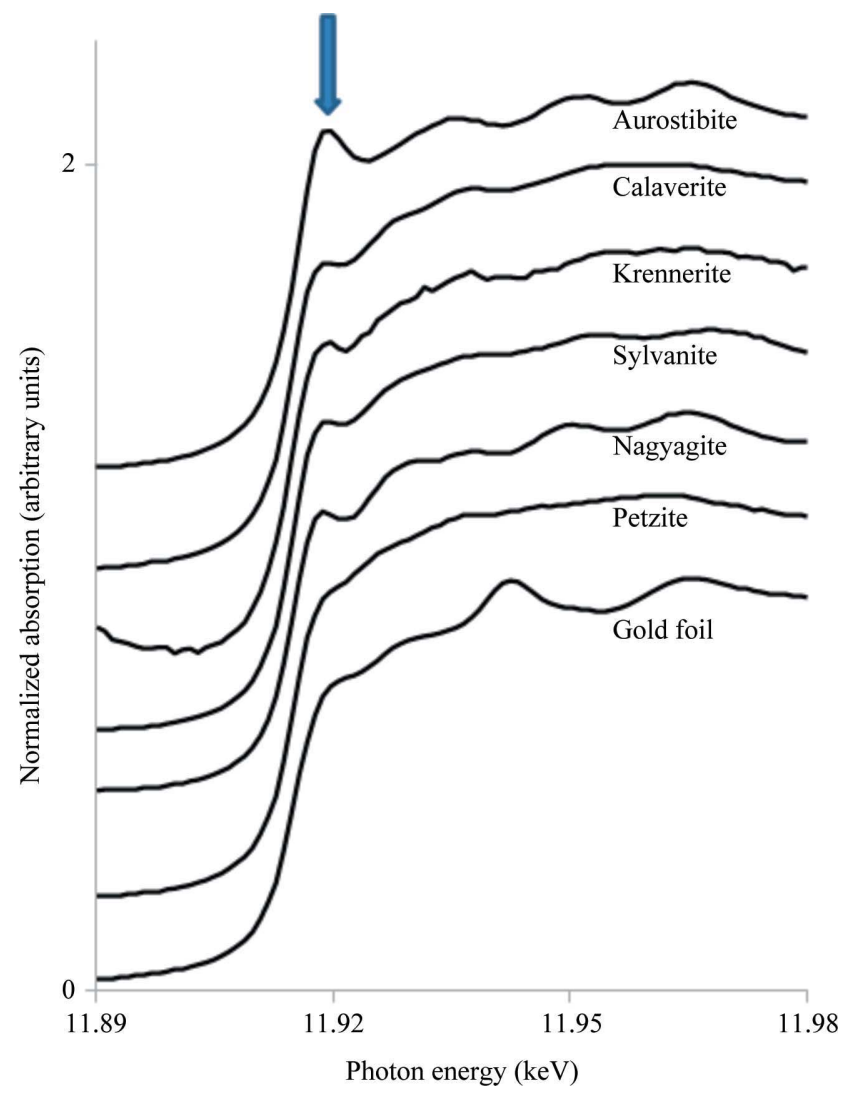

Figure 4

$\mathrm{Au} L_{\mathrm{III}}$-edge XANES spectra for petzite and reference $\mathrm{Au}$ minerals. The arrow indicates the white line at the absorption edges. the metal. Conversely, the absorption edge of the anionobtained electrons shifts to the lower energy side. A chemical shift of the threshold energy at the absorption edge occurs in response to the change in the valence state, and the threshold energy shifts to the lower energy side due to the increase in valence of the anion. The Te $L_{\mathrm{III}}$-edge absorption edge for petzite is located on the lowest energy side among these minerals, and partial electron transfer to Te atoms is recognized.

The maximum value of the first derivative [Fig. 5(b)] represents the position of the maximum gradient in the XANES spectrum showing the threshold energy of the absorption edge (Okudera et al., 2012). When comparing peak intensities and positions in the first derivative of the XANES spectrum [Fig. 5(b)], the first peak on the lowest energy side has the same height as the second peak for Te in petzite and the second peak is at nearly the same energy position as the main peaks in calaverite and nagyágite, $\mathrm{Pb}_{5} \mathrm{Au}(\mathrm{Te}, \mathrm{Sb})_{4} \mathrm{~S}_{5-8}$, a rare sulfide mineral which occurs in association with gold ores. Therefore, it can be concluded that the bonding of $\mathrm{Te}$ in petzite has a partial ionic character and the valence state is intermediate between metallic and anionic. In particular, the supply of electrons from $\mathrm{Au}$ and $\mathrm{Ag}$ seems evident. This is

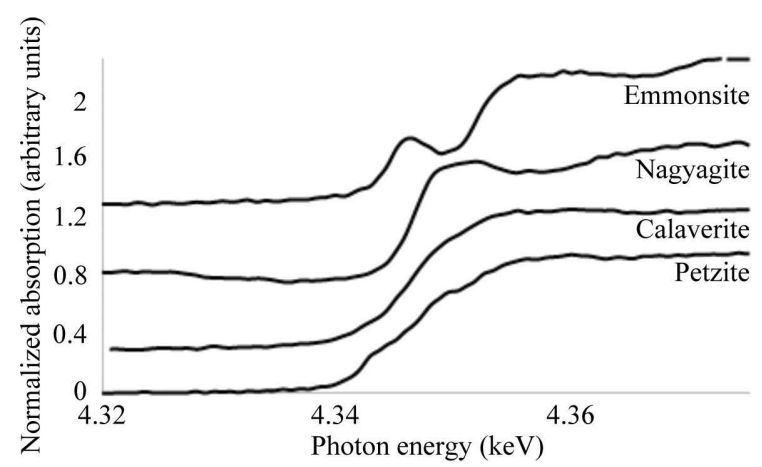

(a)

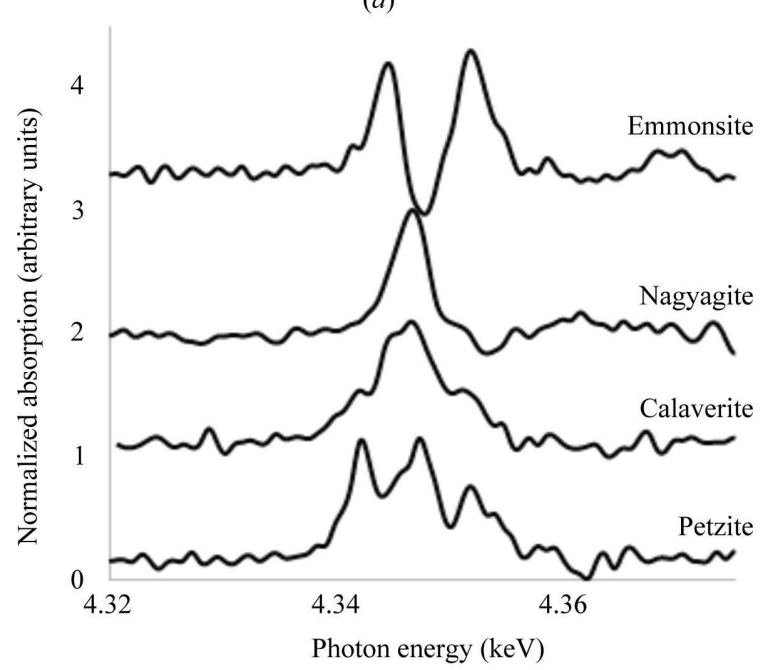

(b)

Figure 5

(a) Te $L_{\mathrm{III}}$-edge XANES spectra of petzite and reference gold compound minerals. (b) First derivatives of the Te $L_{\mathrm{III}}$-edge XANES spectra of petzite and reference gold compound minerals. 
consistent with the Te-Te distance $[\geq 3.767$ (3) $\AA$ ], which is considerably longer than those in calaverite [2.871 (6) $\AA$; Pertlik, 1984] and sylvanite (2.88 Å; Tunell, 1941), as should be expected from the covalent character of the Te-Te bonding in the latter sulfides.

\section{Conclusions}

Petzite has an ideal stoichiometric chemical composition. Impurities such as arsenic and antimony were not detected in our sample. Our structure refinement essentially confirms previous reports, but the absolute structure is actually the opposite with respect to the model. The fact that no attempt to determine the absolute structure was reported in the past casts some doubt on the correctness of the previous reports, unless the opposite enantiomorph was indeed found. Should that be the case, the question of the possible relation between the formation environment and the handedness of the structure naturally arises.

The chemical bonding of $\mathrm{Au}$ in petzite has a more pronounced metallic character than in other gold minerals. The Te $L_{\mathrm{III}}$-edge XANES spectrum in petzite has its absorption edge at the lowest energy among the gold tellurides and partial electron transfer to Te atoms is recognized. The Te bonding in petzite shows a partially ionic character and the valence state is intermediate between metallic and anionic. Interatomic distances for $\mathrm{Ag}-\mathrm{Te}$ in petzite can be interpreted as presenting some ionic contribution to the otherwise covalent nature of the bond. A weak Te-Te bond is suggested both by the interatomic distance, which is shorter than the van der Waals bonding distance, and the geometry of the $\mathrm{Te}-\mathrm{Au} /$ $\mathrm{Ag}$ coordination, and it is likely to be responsible for the brittle nature of petzite crystals.

\section{Acknowledgements}

Critical remarks by two anonymous reviewers are gratefully acknowledged.

\section{References}

Alvarez, S. (2013). Dalton Trans. 42, 8617-8636.

Bindi, L., Arakcheeva, A. \& Chapuis, G. (2009). Am. Mineral. 94, 728-736.

Bindi, L. \& Chapuis, G. (2017). Aperiodic Mineral Structures. In Mineralogical Crystallography. EMU Notes in Mineralogy, Vol. 19, edited by J. Plášil, J. Majzlan and S. Krivovichev. London:
European Mineralogical Union and Mineralogical Society of Great Britain and Ireland.

Busing, W. R. \& Levy, H. A. (1957). Acta Cryst. 10, 180-182.

Chamid, S., Pobedimskaya, E. A., Spiridonov, E. M. \& Belov, N. V. (1978). Sov. Phys. Crystallogr. 23, 267-269.

Christensen, M., Lock, N., Overgaard, J. \& Iversen, B. B. (2006). J. Am. Chem. Soc. 128, 15657-15665.

Cordero, B., Gómez, V., Platero-Prats, A. E., Revés, M., Echeverría, J., Cremades, E., Barragán, F. \& Alvarez, S. (2008). Dalton Trans. 21, 2832-2838.

Flack, H. D. (1983). Acta Cryst. A39, 876-881.

Frueh, A. J. (1959). Am. Mineral. 44, 693-701.

Hiratoko, T., Yoshiasa, A., Nakatani, T., Okube, M., Nakatsuka, A. \& Sugiyama, K. (2013). J. Synchrotron Rad. 20, 641-643.

Hongu, H., Yoshiasa, A., Teshima, A., Isobe, H., Sugiyama, K., Arima, H., Nakatsuka, A., Momma, K. \& Miyawaki, R. (2018). J. Mineral. Petrol. Sci. 113, 152-158.

Momma, K. \& Izumi, F. (2011). J. Appl. Cryst. 44, 1272-1276.

Nakatsuka, A., Shimokawa, M., Nakayama, N., Ohtaka, O., Arima, H., Okube, M. \& Yoshiasa, A. (2011). Am. Mineral. 96, 15931605.

Nespolo, M., Aroyo, M. I. \& Souvignier, B. (2018). J. Appl. Cryst. 51, 1481-1491.

Okudera, H., Yoshiasa, A., Murai, K., Okube, M., Takeda, T. \& Kikkawa, S. (2012). J. Mineral. Petrol. Sci. 107, 127-132.

Pertlik, F. (1984). Z. Kristallogr. 169, 227-236.

Petříček, V., Dusek, M. \& Palatinus, L. (2014). Z. Kristallogr. 229, 345-352.

Reithmayer, K., Steurer, W., Schulz, H. \& de Boer, J. L. (1993). Acta Cryst. B49, 6-11.

Schneider, J. \& Schulz, H. (1993). Z. Kristallogr. 203, 1-15.

Schutte, W. J. \& de Boer, J. L. (1988). Acta Cryst. B44, 486-494.

Shannon, R. D. (1981). Structure and Bonding in Crystals, Vol. 2, edited by M. O'Keeffe \& A. Navrotsky, pp. 53-70. New York: Academic Press.

Thompson, R. M. (1948). Am. Mineral. 33, 209-210.

Thompson, R. M. (1949). Am. Mineral. 34, 341-382.

Tobase, T., Yoshiasa, A., Hiratoko, T. \& Nakatsuka, A. (2018). J. Synchrotron Rad. 25, 1129-1134.

Tokuda, M., Yoshiasa, A., Mashimo, T., Iishi, K. \& Nakatsuka, A. (2018). Acta Cryst. C74, 460-464.

Tunell, G. (1941). Am. Mineral. 26, 457-477.

Venudhar, Y. C., Iyengar, L. \& Krishna Rao, K. V. (1978). J. LessCommon Met. 60, P41-P46.

Willis, B. T. M. \& Pryor, A. W. (1975). Thermal Vibrations in Crystallography. Cambridge University Press.

Wood, I. G., Knight, K. S., Price, G. D. \& Stuart, J. A. (2002). J. Appl. Cryst. 35, 291-295.

Wyckoff, R. W. G. (1963). Cryst. Struct. 1, 7-83.

Yoshiasa, A., Kitahara, G., Tobase, T., Hiratoko, T., Hongu, H., Nakatani, T. \& Murai, K. (2018). Phys. Status Solidi B, 255, 1800050.

Yoshiasa, A., Nakatani, T., Nakatsuka, A., Okube, M., Sugiyama, K. \& Mashimo, T. (2016). Acta Cryst. B72, 381-388. 